\title{
On Photochemical Air Pollution Potential in Southern California Derived from Ozone Data from 16 Monitoring Stations
}

\author{
Brunislav Matasović, ${ }^{\mathrm{a}, *}$ Tomislav Cvitaš, ${ }^{\mathrm{b}}$ and Leo Klasinc ${ }^{\mathrm{a}}$ \\ ${ }^{a}$ Division of Physical Chemistry, Ruđer Bošković Institute, Bijenička c. 54, HR-10002 Zagreb, Croatia \\ ${ }^{\mathrm{b}}$ Department of Chemistry, Faculty of Science, University of Zagreb, Horvatovac 102a, HR-10000 Zagreb, Croatia
}

RECEIVED NOVEMBER 4, 2011; REVISED JANUARY 26, 2012; ACCEPTED JANUARY 31, 2012

\begin{abstract}
Average hourly ozone volume fractions from ten automatic monitoring stations in the Los Angeles and six in the Riverside area for the April through September season in the years 2000 to 2005 have been analysed on the basis of recently introduced photochemical pollution (PP) indicators. Although considerably high indicator values were found for almost all the stations, surprisingly, some (e.g. Palm Springs) exhibit low daily maximum-to-minimum ratios of hourly ozone values which is crucial for assessment of a low PP by the given indicator method, despite the overall high ozone concentrations recorded. At such stations, in contrast to elsewhere, a characteristic quasi normal distribution of all ozone hourly volume fractions exists which could be a consequence of poor vegetation or some special meteorological conditions there. Compared with a similar assessment in central Europe and the Mediterranean region, the present analysis shows that PP problems in California are significant. (doi: 10.5562/cca2008)
\end{abstract}

Keywords: photochemical pollution, pollution indicators, ambient ozone, average hourly ozone data, ozone precursors, growth season

\section{INTRODUCTION}

Despite the enormous importance of ozone in the atmosphere for protecting life on Earth's surface by blocking Sun's UV radiation, because of its oxidizing capacity, elevated ozone concentrations in the planetary boundary layer are harmful to the most life forms. Its natural sources there are transport from the stratosphere by intrusions and from electric discharges that can break oxygen molecules into atoms, but most of it is a consequence of human activities releasing nitrogen dioxide which photolytically yields oxygen atoms to combine with molecular oxygen into ozone. Nitrogen dioxide concentrations in the atmosphere are normally very low (however, its natural sources being wildfires and lightning can under circumstances become quite substantial). ${ }^{1}$ Considerably increased concentrations in ambient air can invariably be associated with human activities (energy production, chemical industry, transport and combustion processes) the increase in ozone volume fractions observed worldwide nowadays (or even the whole amount) is generally considered as pollution. It is also predicted that, most probably, further rise in the tropospheric ozone concentrations will occur in the future $^{2}$ and have effect on crops. ${ }^{3}$ Ozone can be easily and reliably monitored and based on measured average hourly ozone volume fractions a number of indices, directives, air quality standards and limits have been put forward in order to quantify the air quality affecting humans, vegetation and materials. ${ }^{4,5}$ In spite of ozone being the most abundant species in the hazardous atmospheric condition known as photosmog, there are numerous other components present in this reactive brew which cause adverse effects. Based on long-term ozone monitoring results at various locations over $\mathrm{Eu}-$ rope $^{6}$ we realized that along with a high daily value the extent of the diurnal variation expressed as the average of daily maximum-to-minimum ratio $(R)$ gives a much better insight into the atmospheric condition arising from ozone formation in a polluted atmosphere that we call photochemical pollution (PP). Since ozone reaction products - aldehydes, peroxides, radicals, secondary organic aerosols ${ }^{7-10}$ - represent very potent pollution components, new pollution indicators have been devised that take into account corrections of $R$ for the amount of daily ozone production $\left(P_{1}\right)$ and the number of hours the hourly average exceeded a chosen limiting value over a given period $\left(P_{2}\right)$ (usually the vegetation growth season). ${ }^{6,11}$ Also a third indicator defined as their geometrical mean was introduced to take care for possibly

\footnotetext{
* Author to whom correspondence should be addressed. (E-mail: bmatasov@irb.hr)
} 
larger differences between $P_{1}$ and $P_{2}$, and is therefore chosen to be the principal photochemical pollution indicator in our recent analyses. ${ }^{12,13}$ The ozone data from monitoring stations in California seemed to be a good example to test the approach on a really tough problem - assessment of PP at the cradle of Los Angeles smog. The proposed indicators for identification of sites prone to PP have shown good predictive power in the case of central European, Mediterranean (Italy, Slovenia, Croatia), a UK set of stations ${ }^{14}$ and even some stations in the subtropics (Louisiana, Hong Kong).

\section{METHODS}

All the data used, were obtained from the California Environmental Protection Agency (http://www.arb. ca.gov/adam/hourly/hourly1.php) and US Environmental Protection Agency (http:/www.epa.gov/ttn/airs/ airsaqs/detaildata/downloadaqsdata.htm). The locations of all monitoring sites are given in Table 1 and shown on the map in Figure 1. All data, originally shown vol- ume fractions in ppm, were simply converted to volume fractions in $\mathrm{ppb}$.

The calculation method has been described previously $^{6,11,12}$ and was developed by analysing ten years of ozone data from twelve EMEP (European Monitoring and Evaluation Programme) stations over Europe. The indicators are defined as:

$$
\begin{aligned}
& P_{1}=R M / A \\
& P_{2}=R\left(1+168 \cdot t_{\mathrm{exc}} / N\right) \\
& P_{3}=\sqrt{P_{1} \cdot P_{2}}
\end{aligned}
$$

where $R$ is the average of daily maximum-to-minimum ratios, $M$ is the seasonal average of daily maximum values, $A$ is the average of all seasonal data, $t_{\mathrm{exc}}$ is the duration in hours the limit of 80 ppb was exceeded ("excess time") and $N$ is the total number of hourly averages of ozone volume fractions measured over some period

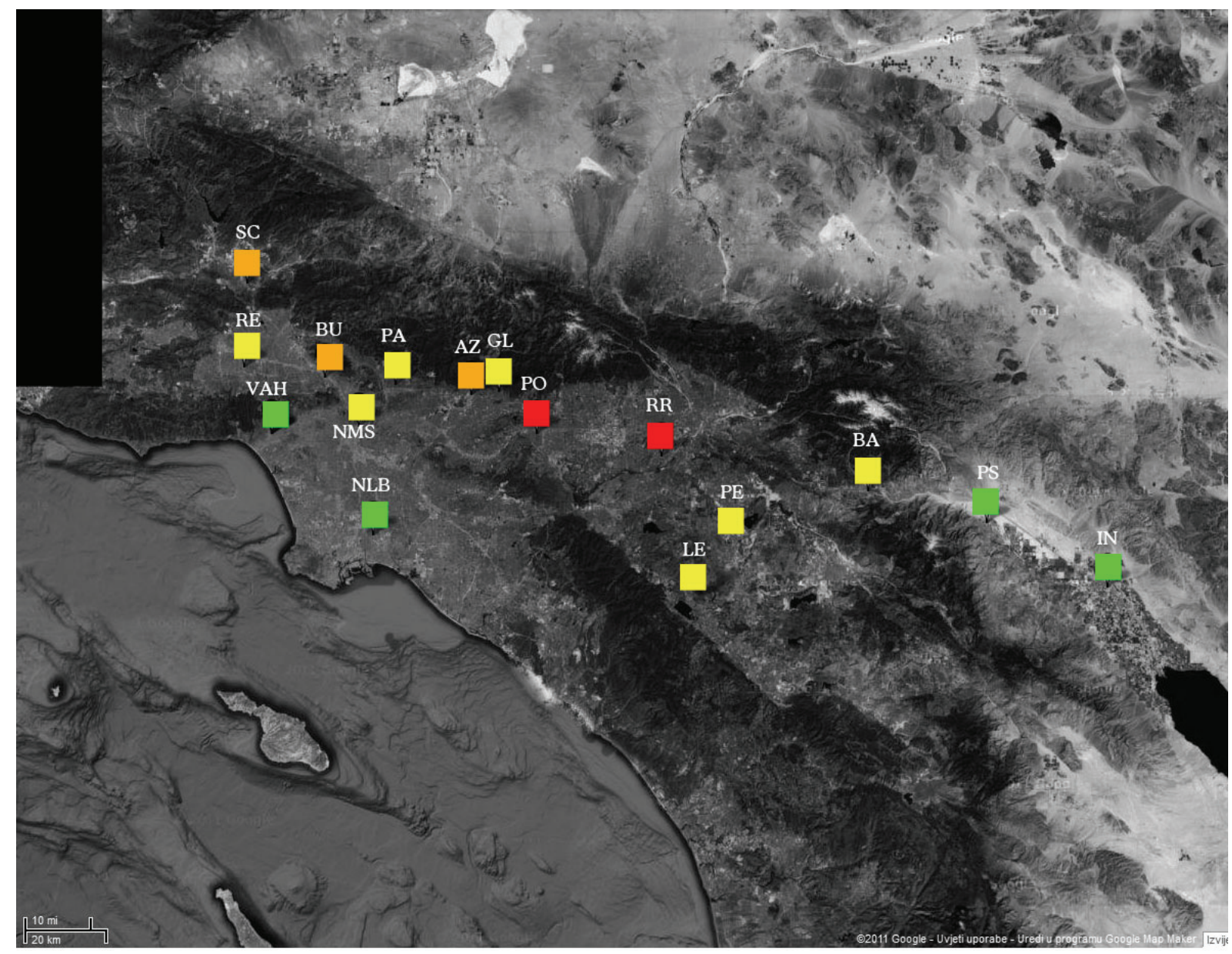

Figure 1. Map of the Greater Los Angeles Area with indicated monitoring sites. The colour codes for the $P_{3}$-indicators are as follows: green $\left(P_{3}<70\right)$, yellow $\left(70<P_{3}<140\right)$, orange $\left(140<P_{3}<210\right)$ and red $\left(P_{3}>210\right)$. The names of the stations, abbreviations and their geographical coordinates are given in Table 1. 
Table 1. Geographical coordinates of 16 investigated monitoring sites

\begin{tabular}{lcccc}
\hline Monitoring station & Abbreviation & N Latitude $/{ }^{\circ}$ & W Longitude $/{ }^{\circ}$ & Altitude $/ \mathrm{m}$ \\
\hline Azusa & AZ & 34.136 & 117.924 & 182 \\
LA VA Hospital & VAH & 34.051 & 118.457 & 61 \\
Santa Clarita & SC & 34.383 & 118.528 & 375 \\
Burbank & BU & 34.176 & 118.317 & 10 \\
Glendora & GL & 34.144 & 117.850 & 84 \\
LA North Main Street & NMS & 34.066 & 118.227 & 87 \\
North Long Beach & NLB & 33.824 & 118.189 & 6 \\
Pasadena & PA & 34.133 & 118.127 & 250 \\
Pomona & PO & 34.067 & 117.750 & 270 \\
Reseda & RE & 34.199 & 118.533 & 69 \\
Indio & IN & 33.708 & 116.216 & -4 \\
Palm Springs & PS & 33.853 & 116.541 & 171 \\
Lake Elsinore & LE & 33.676 & 117.331 & 1449 \\
Banning Airport & BA & 33.921 & 116.858 & 473 \\
Perris & PE & 33.789 & 117.228 & 442 \\
Riverside-Rubidoux & RR & 34.001 & 117.415 & 250 \\
\hline
\end{tabular}

of time (usually the growth season). The 168 factor in $P_{2}$ arises from the arbitrary 1 hour/week average excess time that, if present, would double the $R$ value.

Both indicators are based on daily maximum-tominimum ratios. The minimum value is set to 0.8 if recorded as zero in accordance with the detection limit of the instruments.

All indicators depend crucially on the value of $R$. Since $R$ is the ratio of daily maximum and minimum hourly volume fractions, thus indirectly reflecting the daily ozone turnover, the indicators may also be a valid measure for adverse effects on living organisms and materials. However, especially the low, close to zero, values affect the average ratio strongly and hence the indicator values. This may also be seen from the frequency distribution of measured values which were analysed here, as well.

\section{RESULTS AND DISCUSSION}

The results for all the mentioned stations are shown in Table 2. Data in the table include (in the order of the columns) location, name of the station followed by corresponding average values of the ozone volume fraction $(A / \mathrm{ppb})$, average of daily maximum-tominimum ratios $(R)$, average of daily maxima $(M / \mathrm{ppb})$, average excess time during which the $80 \mathrm{ppb}$ limit was exceeded $\left(t_{\mathrm{exc}} / \mathrm{h}\right)$ and averages of indicators $P_{1}, P_{2}$ and $P_{3}$. The last column gives the total number of recorded and validated hourly average ozone volume fractions. Data in the table include period from April to September in each year. For every station except Perris, 6-year period from 2000 to 2005 has been covered. (Perris had not enough data for 2005 and this year was excluded). Annual differences between data from the same station do not indicate any significant trend neither toward lower nor to higher values of ozone in the atmosphere.

One can observe that indicators $P_{1}$ and $P_{2}$ often contribute to $P_{3}$ very differently - the influence of $P_{2}$ being much higher in almost all cases (with the exception of LA VA Hospital). It was found previously ${ }^{6}$ that for stations in moderate climate regions the values of $P_{1}$ and $P_{2}$ did not differ much for a given station and the number of hours above the threshold of $80 \mathrm{ppb}$ was usually quite low.

Table 2 shows that photochemical pollution in California is substantial indeed. According to our previous analysis ${ }^{6}$ sites with indicator values greater than 40 should be classified as medium polluted, and those with indicator values above 100 as polluted. During the seasonal period, only two of the 16 investigated stations: Palm Springs and NLB, have a $P_{3}$-indicator value (as 6 years average) lower than 40 , while 10 of them exceeded the value of 100. An alternative grouping of the sites in ranges of 70 units for $P_{3}$ yields four as low to medium $\left(P_{3}<70\right)$, seven as substantially $\left(70<P_{3}<140\right)$, three as heavily $\left(140<P_{3}<210\right)$ and two as extremely polluted sites $\left(P_{3}>210\right)$ : Pomona with 220 and Riverside-Rubidoux with 300 . For comparison, $P_{3}$-values for three Louisiana stations (8-year averages), which are at similar latitude, were between 57 and 71, while the highest value determined for the Pearl River Delta station at Luhu Guangzhou (China) for months June November 2006 was $277 .{ }^{12}$ 
Table 2. Characteristic parameters of ambient ozone fractions obtained for the growth season at 16 monitoring sites in the Greater Los Angeles area

\begin{tabular}{lcccccccc}
\hline Monitoring station & $A / \mathrm{ppb}$ & $R$ & $M / \mathrm{ppb}$ & $t_{\mathrm{exc}} / \mathrm{h}$ & $P_{1}$ & $P_{2}$ & $P_{3}$ & $N$ \\
\hline Azusa & 28.4 & 42.6 & 71 & 185 & 110 & 350 & 190 & 25140 \\
LA VA Hospital & 31.7 & 31.0 & 59 & 41 & 60 & 70 & 63 & 25058 \\
Santa Clarita & 38.8 & 31.8 & 85 & 423 & 70 & 580 & 200 & 24600 \\
Burbank & 27.9 & 44.2 & 68 & 147 & 110 & 280 & 180 & 24948 \\
Glendora & 34.9 & 19.4 & 78 & 281 & 44 & 230 & 99 & 25079 \\
LA North Main Street & 26.2 & 35.3 & 60 & 60 & 83 & 120 & 97 & 24597 \\
North Long Beach & 28.6 & 12.5 & 50 & 9 & 22 & 18 & 20 & 25129 \\
Pasadena & 30.7 & 26.2 & 70 & 172 & 60 & 190 & 110 & 25099 \\
Pomona & 25.6 & 50.9 & 67 & 158 & 130 & 380 & 220 & 25143 \\
Reseda & 35.3 & 25.3 & 73 & 255 & 53 & 260 & 110 & 25158 \\
Indio & 47.8 & 13.5 & 72 & 270 & 21 & 160 & 56 & 25394 \\
Palm Springs & 55.4 & 4.5 & 81 & 502 & 6.5 & 94 & 25 & 25029 \\
Lake Elsinore & 42.6 & 25.1 & 80 & 366 & 47 & 380 & 130 & 24744 \\
Banning Airport & 48.7 & 21.2 & 85 & 516 & 37 & 480 & 130 & 24528 \\
Perris & 42.1 & 19.0 & 84 & 462 & 39 & 380 & 120 & 21183 \\
Riverside-Rubidoux & 36.8 & 48.6 & 82 & 413 & 110 & 850 & 300 & 24963 \\
\hline
\end{tabular}

The variations in the indicator values from year to year are not very large and usually within 30 to $40 \%$ expressed as relative standard deviations. This means that only two figures in the indicator values can be taken as significant. Variations for very large displacements of sites are, of course, larger, but too little is known (too few data analyzed) at present to allow us to draw meaningful conclusions.

It needs to be noted that two of the stations with the lowest $P_{3}$ values - Palm Springs and Indio - are located in the desert valley surrounded by mountains, while the other two - NLB and LA VA Hospital - are located close to the sea. Lack of vegetation and local conditions (e.g. lack of nitrogen oxides at night ${ }^{15}$ may be the reasons; unusually low $P_{3}$-values were also found for the coastal stations in Hong Kong. ${ }^{12}$

The low $P_{3}$-values are a consequence of low $R$ values at Palm Springs and Indio stations. In spite of the yearly average of over 500 hours with ozone fractions in excess of $80 \mathrm{ppb}$ which occur here, the $P_{3}$-values remain low because of the small difference between the daily maximum and minimum values. The high values could be a consequence of ozone and ozone-precursor transport from neighbouring locations, yet no significant destruction takes place owing to scarce vegetation and hardly any deposition to desert sand. ${ }^{16}$ Consequently, although experiencing high ozone values, these sites, because of comparatively low ozone destruction, exhibit relatively low $P_{3}$-values and belong to medium PP according to the described scheme.
On the other hand, sites such as Azusa, Santa Clarita, Riverside-Rubidoux and Pomona have extremely high $P_{3}$-values indicative of photochemically most polluted sites, such as some found in the Pearl River Delta (PRD) area. ${ }^{12}$ High daily ozone production in this area is accompanied with high ozone consumption by volatiles and aerosols in the air.

If average data for the whole years are compared with seasonal values in Table 2, the monthly averages and averages of daily maxima of ozone concentrations for all stations are significantly lower (30\%) and more than $95 \%$ of excess time is observed during the growth season (compared with $95 \%$ in Sicily, Italy, $91 \%$ in Louisiana, USA, but only $84 \%$ in PRD, China). ${ }^{12}$ Because low values of average ozone hourly data do critically affect the $R$-value and finally the PP assessment we compared the shape of the ozone data frequency distribution during the growth season with the indicator $P_{3}$ calculated here for the California stations.

The frequency distributions of ozone volume fractions are represented by histograms of a box-width of 5 ppb, Figure 2. For sites with low $P_{3}$-values the distribution shows a quasi-normal (Gaussian) shape while for sites with high $P_{3}$-values a much higher frequency of low ozone volume fractions can be seen. Analogously the cumulative probability distribution generally following a sigmoidal curve becomes more spread out as the $P_{3}$-indicator increases. This is to be expected since the indicators are largely determined by the average daily maximum-to-minimum ratio, $R$, which increases with the spread of measured values. 


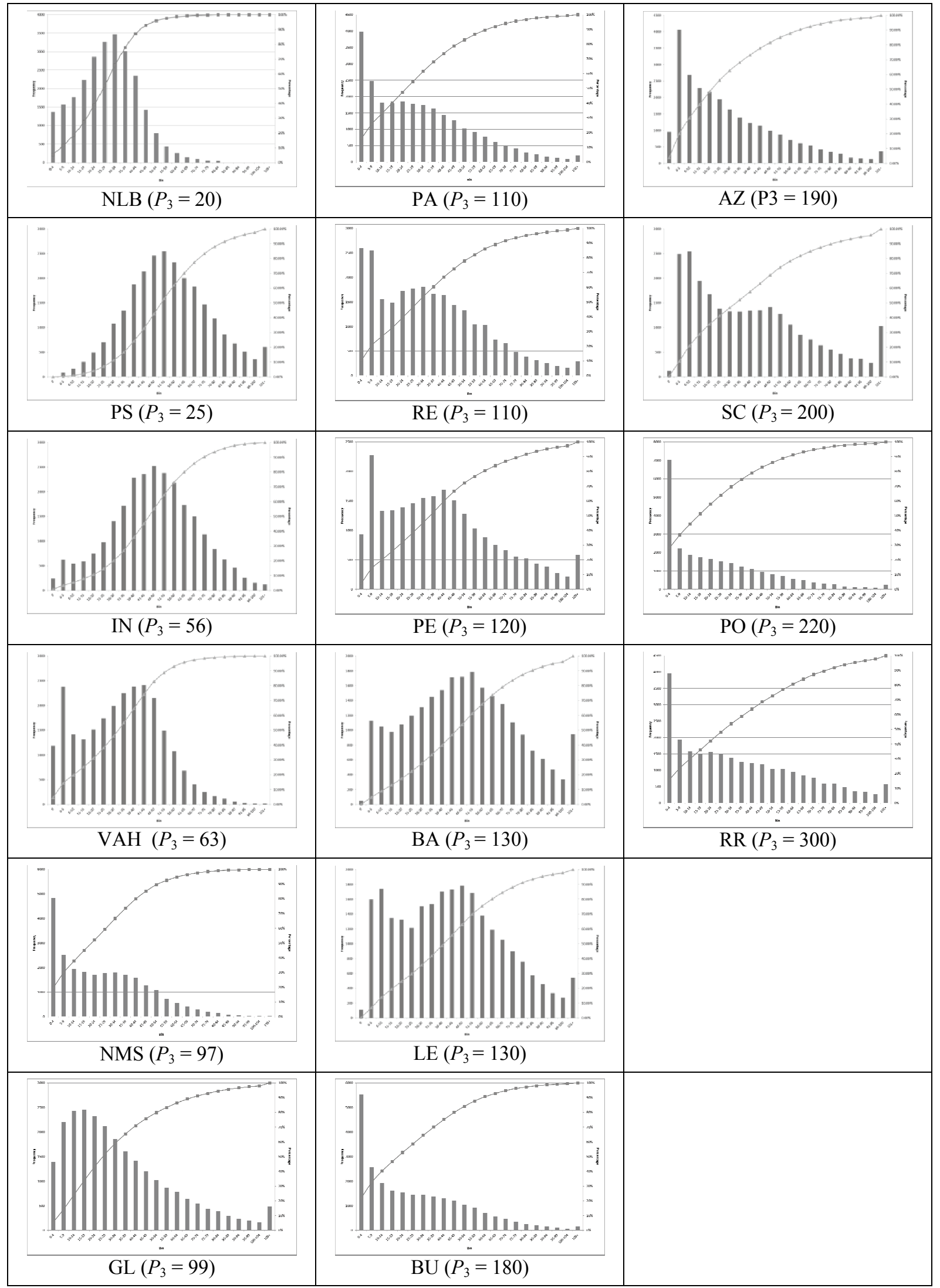

Figure 2. Histogram representations of frequency distributions of seasonal ambient ozone fractions (in 5 ppb intervals) and calculated $P_{3}$-indicator values for 16 Californian stations. Station abbreviations are given in Table 1. 


\section{CONCLUSION}

The present assessment of PP at some stations in the Los Angeles and Riverside regions during the growth season from April through September based on indicator determination from ozone data between 2000-2005 shows the sites to be prone to PP, however, with relatively large differences found (e.g. for Palm Springs and Riverside) between them. The comparison with the data for the whole year shows that the growth season has been adequately chosen because less than $5 \%$ of the measured ozone volume fractions exceeding the $80 \mathrm{ppb}$ threshold occur outside the season similar as in Europe, and less than in Louisiana where it is ca. $15 \%$ or the Pearl River Delta region where $30 \%$ of the excess times lie outside the April to September period. Although the indicator values do differ for years at a station as well as between the stations a general pattern of high PP in the region is clearly observable (see Map). The indicators reflect the distribution of hourly average ozone volume fractions. High indicator values are associated with a high frequency (significantly higher than in a normal distribution).

Acknowledgements. This work has been financially supported by the Ministry of Science, Education and Sports of the Republic of Croatia (Project code 098-0982915-2947).

\section{REFERENCES}

1. S. F. Müller and J. W. Mallard, Model. Environ. Sci. Technol. 45 (2011) 4817-4823.

2. D. S. Stevenson, F. J. Dentener, M. G. Schultz, K. Ellingsen, T. P. C. van Noije, O. Wild, G. Zeng, M. Amann, C. S. Atherton, N. Bell, D. J. Bergmann, I. Bey, T. Butler, J. Cofala, W. J. Collins, R. G. Derwent, R. M. Doherty, J. Drevet, H. J. Eskes, A. M. Fiore, M. Gauss, D. A. Hauglustaine, L. W. Horowitz, I. S. A. Isaaksen, M. C. Krol, J.-F. Lamarque, M. G. Lawrence, V. Montanaro, J.-F. Müller, G. Pitari, M. J. Prather, J. A. Pyle, S. Rast, J. M. Rodriquez, M. G. Sanderson, N. H. Savage, D. T.
Shindell, S. E. Strahan, K. Sudo, and S. Szopa, J. Geophys. Res. - Atmos. 111 (2006) D08301.

3. J. Giles, Nature 435 (2005) 7.

4. Manual on methodologies and criteria for modelling and mapping critical loads \& levels and air pollution effects, risks and trends. ICP Mapping and Modelling; UNECE CLRTAP; ICP, 2004., http://www.rivm.nl/thema/images/mapman-2004_tcm6148383.pdf (accessed: October 11, 2011)

5. E. Paoletti, A. de Marco, and S. Racalbuto, Environ. Monit. Assess. 128 (2007) 19-30.

6. E. Kovač-Andrić, G. Šorgo, N. Kezele, T. Cvitaš, and L. Klasinc, Environ. Monit. Assess. 165 (2010) 577-583.

7. J. L. Jimenez, M. R. Canagaratna, N. M. Donahue, A. S. H. Prevot, Q. Zhang, J. H. Kroll, P. F. deCarlo, J. D. Allan, H. Coe, N. L. Ng, A. C. Aiken, K. S. Docherty, I. M. Ulbrich, A. P. Grieshop, A. L. Robinson, J. Duplissy, J. D. Smith, K. R. Wilson, V. A. Lanz, C. Hueglin, Y. L. Sun, J. Tian, A. Laaksonen, T. Raatikainen, J. Rautiainen, P. Vaattovaara, M. Ehn, M. Kulmala, J. M. Tomlinson, D. R. Collins, M. J. Cubison, E. J. Dunlea, J. A. Huffman, T. B. Onasch, M. R. Alfarra, P. I. Williams, K. Bower, Y. Kondo, J. Schneider, F. Drewnick, S. Borrmann, S. Weimer, K. Demerjian, D. Salcedo, L. Cottrell, R. Griffin, A. Takami, T. Miyoshi, S. Hatakeyama, A. Shimono, J. Y. Sun, Y. M. Zhang, K. Džepina, J. R. Kimmel, D. Sueper, J. T. Jayne, S. C. Herndon, A. M. Trimborn, L. R. Williams, E. C. Wood, A. M. Middlebrook, C. E. Kolb, U. Baltensperger, and D. R. Worsnop, Science 326 (2009) 1525-1529.

8. J. N. Cape, Environ. Pollut. 155 (2008) 391-397.

9. N. M. Donahue, A. L. Robinson, and S. N. Pandis, Atmos. Environ., 43 (2009) 94-106.

10. E. C. Wood, S. C. Herndon, T. B. Onasch, J. H. Kroll, M. R. Canagaratna, C. E. Kolb, D. R. Wornsop, J. A. Neuman, R. Seila, M. Zavala, and W. B. Knighton, Atmos. Chem. Phys., 9 (2009) 2499-2517.

11. L. Klasinc, T. Cvitaš, A. de Marco, N. Kezele, E. Paoletti, and M. Pompe, Fresen. Environ. Bull. 19(9B) (2010) 1982-1988.

12. L. Klasinc, T. Cvitaš, S. P. McGlynn, M. Hu, X. Tang, and Y. Zhang, Croat. Chem. Acta 84 (2011) 11-16.

13. T. Cvitaš, L. Klasinc, B. Matasović, and S. P. McGlynn, Int. J. Chem. Model. (2012) accepted

14. M. E. Jenkin, Atmos. Environ. 42 (2008) 5434-5445.

15. L. J. Clapp and M. E. Jenkin, Atmos. Environ. 35 (2001) 63916405.

16. H. Güsten, G. Heinrich, E. Mönnich, D. Sprung, J. Weppner, A. B. Ramadan, M. R. M. E. El-Din, D. M. Ahmed, G. K. Y. Hassan, Atmos. Environ. 30 (1996) 911-918. 